\title{
K3[C3N3(COO)3] · 2 H2O - Crystal Structure of a New Alkali Derivative of the Multidentate Ligand Triazine Tricarboxylate
}

\begin{tabular}{|c|c|}
\hline Journal: & Zeitschrift für Anorganische und Allgemeine Chemie \\
\hline Manuscript ID: & zaac. 201000245.R1 \\
\hline Wiley - Manuscript type: & Article \\
\hline $\begin{array}{r}\text { Date Submitted by the } \\
\text { Author: }\end{array}$ & 19-Jul-2010 \\
\hline Complete List of Authors: & $\begin{array}{l}\text { Makowski, Sophia J.; LMU Munich, Chemistry } \\
\text { Hörmannsdorfer, Michael; LMU Munich, Chemistry } \\
\text { Schnick, Wolfgang; LMU Munich, Chemistry }\end{array}$ \\
\hline Keywords: & s-Triazine, Potassium, Carboxylate ligand, Crystal structure \\
\hline
\end{tabular}

\section{SCHOLARONE ${ }^{\text {M }}$ Manuscripts}




\title{
$\mathrm{K}_{3}\left[\mathrm{C}_{3} \mathrm{~N}_{3}(\mathrm{COO})_{3}\right] \cdot 2 \mathrm{H}_{2} \mathrm{O}$ - Crystal Structure of a New Alkali Derivative of the Multidentate Ligand Triazine Tricarboxylate
}

\author{
Sophia J. Makowski, Michael Hörmannsdorfer and Wolfgang Schnick*
}

Keywords: $s$-Triazine; Potassium; Carboxylate ligands; Crystal structure

\begin{abstract}
Potassium-1,3,5-triazine-2,4,6-tricarboxylate dihydrate $\mathrm{K}_{3}\left[\mathrm{C}_{3} \mathrm{~N}_{3}(\mathrm{COO})_{3}\right] \cdot 2 \mathrm{H}_{2} \mathrm{O}$ was obtained by saponification of the respective ethyl ester in aqueous solution under mild conditions and subsequent crystallization at $4{ }^{\circ} \mathrm{C}$. The crystal structure of the molecular salt was elucidated by single-crystal X-ray diffraction $(P 1, a=6.9663(14), b=17.485(3)$, $\left.c=17.560(3) \mathrm{pm}, \alpha=119.73(3), \beta=91.96(3), \gamma=93.84(3)^{\circ}, V=1847.6(6) \cdot 10^{6} \mathrm{pm}^{3}, Z=6, \mathrm{~T}=200 \mathrm{~K}\right)$. Perpendicular to [100] the triazine tricarboxylate and potassium ions are arranged in layers alternating with layers of crystal water molecules. Two thirds of the triazine tricarboxylate units form hexagonal channels being filled with the remaining triazine tricarboxylate molecules. $\mathrm{K}_{3}\left[\mathrm{C}_{3} \mathrm{~N}_{3}(\mathrm{COO})_{3}\right] \cdot 2 \mathrm{H}_{2} \mathrm{O}$ was additionally investigated by means of FTIR spectroscopy, TG and DTA measurements.
\end{abstract}

\author{
* $\quad$ Prof. Dr. W. Schnick \\ Department Chemie \\ Lehrstuhl für Anorganische Festkörperchemie \\ Ludwig-Maximilians-Universität München \\ Butenandtstraße 5-13 (D) \\ D-81377 München, Germany \\ Fax: +49-(0)89-2180-77440 \\ E-mail: wolfgang.schnick@uni-muenchen.de
}

\section{Introduction}

Research in the field of carbon nitrides is mainly focused on the synthesis of two- and three-dimensional networks which can serve as functional materials for a wide field of applications such as catalysis or optoelectronic uses [1-3]. A common approach towards multidimensional networks is the pyrolysis of $s$-triazine $\left(\mathrm{C}_{3} \mathrm{~N}_{3}\right)$ or $s$-heptazine $\left(\mathrm{C}_{6} \mathrm{~N}_{7}\right)$ based precursors to induce condensation and thereby generating covalently bound products. A variety of precursors with different functional groups has been utilized in this regard (cf. Scheme 1, 1a-d and 2a-d) [4-8].

In general, molecules containing residues that are bound to the $s$-triazine or $s$-heptazine core via $\mathrm{C}$ - $\mathrm{C}$ bonds (cf. Scheme 1 , 1e-f and 2e-f) are adverse in this regard. This is due to the strength of the $\mathrm{C}-\mathrm{C}$ bonds impeding a successful condensation. Furthermore, the synthesis of carbon nitrides necessitates an alternating sequence of carbon and nitrogen both in the precursor and in the resulting polymeric network. Even though such compounds are no suitable precursors for the synthesis of covalently bound true carbon nitrides by condensation reactions they can be regarded as promising linkers in coordination polymers. Metal organic frameworks (MOFs) have been extensively studied in the last years due to their potential applications, e. g. as materials for ion exchange, separation, catalysis or gas storage $[9,10]$. While numerous MOFs are known in which a hydrocarbon cycle functionalized with several carboxylate groups, e. g. trimesic acid 3 (cf. Scheme 2) [1113], serves as the linker between inorganic centers the analog $s$-triazine or $s$-heptazine compounds $\mathbf{1 f}$ and $2 \mathbf{f}$ have not been employed for this purpose so far.

In known $s$-triazine and $s$-heptazine based linkers such as $s$-triazine-2,4,6-tris(4-pyridyl) 4 [14,15], $s$-triazine-2,4,6-triyltribenzoic acid 5 [16-20] or $s$-heptazine-2,5,8-triyl-tribenzoic acid 6 [20,21] (cf. Scheme 2) the $s$-triazine or $s$-heptazine cores, respectively, only provide the threefold symmetry but do not contribute to metal coordination. In contrast in $\mathbf{1 f}$ and $\mathbf{2 f}$ both the carboxylate groups and the nitrogen atoms of the ring can be regarded as coordination positions.

The $s$-heptazine compound $\mathbf{2 f}$ has not been mentioned in the literature so far whereas the synthesis of $\mathbf{1 f}$ by a multistep reaction via the respective ethyl ester and potassium salt has already been described over 50 years ago [22]. However, no structural characterization of the product or any intermediate has been performed and since then only very little research regarding triazine tricarbonic acid or its salts has been carried out until 2002 when Dunbar et al. reported the crystal structure and magnetic properties of $\mathrm{K}\left\{\mathrm{Fe}(1,3,5\right.$-triazine-2,4,6-tricarboxylate $\left.)\left(\mathrm{H}_{2} \mathrm{O}\right)_{2}\right\} \cdot 2 \mathrm{H}_{2} \mathrm{O}$ [23].

To the best of our knowledge no crystal structure of any other salt of triazine tricarbonic acid has been described so far. However, regarding the potential application of triazine tricarboxylate as a multidentate ligand a deeper understanding of its 
coordination behavior towards various metal ions is of great interest. In this contribution we report on synthesis and crystal structure of potassium triazine tricarboxylate dihydrate as a further example of a structurally characterized triazine tricarboxylate and thereby providing further insight into the coordination properties of this linker.

\section{Results and Discussion}

\section{Crystal Structure}

Potassium triazine tricarboxylate crystallizes as a dihydrate in the triclinic space group $P \overline{1}$ with six formula units in the unit cell. Crystallographic data and details of the structure refinement are summarized in Table 1. The crystal structure comprises triazine tricarboxylate $\left[\mathrm{C}_{3} \mathrm{~N}_{3}(\mathrm{COO})_{3}\right]^{3-}$ and potassium ions and crystal water molecules (cf. Figure 1).

The triazine tricarboxylate ions are nearly planar with only the carboxylate groups being slightly rotated out of plane so that the anions exhibit molecular symmetry $C_{3}$. The substituents cause an increase of the adjacent angles $\left(\mathrm{N} 1-\mathrm{C} 1-\mathrm{N} 3=124.5^{\circ}\right)$ while the remaining angles of the $s$-triazine core are accordingly reduced $\left(\mathrm{C} 1-\mathrm{N} 1-\mathrm{C} 2=115.5^{\circ}\right)$. In accordance with expectation the bond distances of both the $\mathrm{C}-\mathrm{N}$ bonds within the ring (133-134 pm) and the C-O bonds of the carboxylate groups (124-125 pm) correspond to conjugated double bonds while the C-C bond lengths of 153-154 pm resemble those of single bonds (cf. Table 2).

The triazine tricarboxylate ions, the potassium atoms and water molecules are arranged in an AA'BB' type stacking pattern perpendicular to [100] (cf. Figure 2) with the A and A' layers consisting of the triazine tricarboxylate and potassium ions and the crystal water molecules being located in the intermediate B and B' layers. Within the A and A' layers the triazine tricarboxylate ions are not coplanar but are slightly tilted out of the $b c$-plane. Perpendicular to [100] the triazine tricarboxylate units form two different kinds of columns. One third of the columns consist solely of molecules B (cf. Figure 1) with the molecules of two adjacent layers $\mathrm{A}$ and $\mathrm{A}^{\prime}$ being rotated by $60^{\circ}$ within the plane. In the remaining columns molecules $\mathrm{A}$ and $\mathrm{C}$ alternate and are rotated by $30^{\circ}$. These columns form hexagonal channels around the $\mathrm{B}$ columns (cf. Figure 3).

The interlayer distance of $347 \mathrm{pm}$ between two triazine tricarboxylate layers is in the expected range for molecular $s$ triazine derivatives $[1,24,25]$. Between the layers the triazine tricarboxylate units are interconnected by a network of medium strong [26] hydrogen bonds (cf. Table 3) via the carboxylate groups. All crystal water molecules are part of the hydrogen bonding network although due to the strong disorder of one oxygen atom (O24) no hydrogen bond can be clearly assigned to the linked hydrogen atom $\mathrm{H} 11$.

The potassium ions are coordinated in the form of irregular polyhedrons by four to six oxygen atoms of water molecules and carboxylate groups and by one nitrogen atom of the triazine rings. The triazine tricarboxylate units serve as tridentate ligands and coordinate the $\mathrm{K}^{+}$atoms via the $\mathrm{O}-\mathrm{N}-\mathrm{O}$ entities (cf. Figure 1 ) with the $\mathrm{K}^{+}$atom being slightly shifted towards one of the oxygen atoms. The coordination sphere is completed by the oxygen atoms of further triazine tricarboxylate units and water molecules. The K-O distances (273-297 pm) are in accordance with the sum of the ionic radii [27] while the K-N distances $(278-282 \mathrm{pm})$ are relatively short compared to the potassium salts of other $s$-triazine or $s$-heptazine compounds [28-30]. In $\mathrm{K}\left\{\mathrm{Fe}(1,3,5\right.$-triazine-2,4,6-tricarboxylate $\left.)\left(\mathrm{H}_{2} \mathrm{O}\right)_{2}\right\} \cdot 2 \mathrm{H}_{2} \mathrm{O}$ the $\mathrm{Fe}$ atoms are coordinated by an $\mathrm{O}-\mathrm{N}-\mathrm{O}$ unit in a similar way as in the title compound with a short Fe-N distance of $212 \mathrm{pm}$ while the potassium ions are coordinated solely by oxygen atoms and the K-O distances are comparable in both compounds. Hence in both triazine tricarboxylate salts a strong contribution of the $s$-triazine core to metal coordination is observed so that the triazine tricarboxylate unit can be regarded as an interesting linker for coordination networks potentially allowing other linkage motifs than those observed in MOFs which contain trimesic acid as the organic linker.

\section{Vibrational Spectroscopy}

Potassium triazine tricarboxylate dihydrate was analyzed by FTIR spectroscopy. All signals in the spectrum can be attributed to vibrations of the triazine tricarboxylate entities and water molecules, respectively (cf. Figure 4). The bending and stretching vibrations of the $s$-triazine ring lead to a characteristic absorption band at $740 \mathrm{~cm}^{-1}$ and a group of signals at $1300-1660 \mathrm{~cm}^{-1}$, respectively. In the range between 1300 and $1660 \mathrm{~cm}^{-1}$ the stretching vibrations of the carboxylate groups can be observed as well. The broad band at $3000-3600 \mathrm{~cm}^{-1}$ can be attributed to the OH stretching vibrations of the crystal water molecules and in accordance with the crystal structure the red-shift of the $v(\mathrm{OH})$ signals corresponds to medium strong hydrogen bonds [26].

\section{Thermal Behavior}

TG and DTA curves of potassium triazine tricarboxylate dihydrate are displayed in Figure 5. In the temperature range between 65 and $150{ }^{\circ} \mathrm{C}$ the crystal water molecules are released (mass loss observed: $10.9 \%$, calculated: $9.9 \%$ ) and the so obtained dehydrated compound is thermally stable up to $325^{\circ} \mathrm{C}$. The decomposition of the sample starts with a mass loss of 
$17 \%$ accompanied by a sharp endothermic signal at $325-390{ }^{\circ} \mathrm{C}$, probably due to a partial decarboxylation, and proceeds with a slow and steady mass loss at higher temperatures.

\section{Conclusions}

We have reported on the crystal structure and thermal behavior of potassium triazine tricarboxylate dihydrate. Triazine tricarboxylate represents a multidentate ligand which can be regarded as the $s$-triazine analog of trimesic acid and hence as a promising linker for metal organic frameworks but only one triazine tricarboxylate salt has been structurally characterized so far. This study has expanded the investigations of this class of compounds to a new salt and thereby provides further insight into the coordination properties of triazine tricarboxylate. The presented crystal structure shows that the nitrogen atoms of the $s$-triazine cycle exhibit a strong interaction with the potassium ions and that the coordination of metal ions via the O-N-O units of the triazine tricarboxylate entities is a recurring binding motif for this ligand. Because of the differing coordination properties compared to trimesic acid triazine tricarboxylate seems to be an interesting linker for coordination networks and with the observed high thermal stability of $\mathrm{K}_{3}\left[\mathrm{C}_{3} \mathrm{~N}_{3}(\mathrm{COO})_{3}\right]$ an important condition for syntheses of three-dimensional networks at elevated temperatures is fulfilled.

\section{Experimental Section}

\section{Syntheses}

Potassium triazine tricarboxylate dihydrate was synthesized according to the procedure described in [22,31] by saponification of the respective triethyl ester. To prepare the triethyl ester dry $\mathrm{HCl}$ was conducted through ethyl cyanoformate $(20.0 \mathrm{~g}, 202 \mathrm{mmol}$, Aldrich, $99 \%$ ) under argon until the trimerization product started to precipitate. Then the conversion was completed by cooling the reaction to $4{ }^{\circ} \mathrm{C}$ over night. The product was filtered, washed with cold water and dried at $75{ }^{\circ} \mathrm{C}$ yielding $7.15 \mathrm{~g}(24.1 \mathrm{mmol}, 36 \%)$ triethyl-s-triazine2,4,6-tricarboxylate as colorless needles.

Elemental analysis (wt. \%): N 14.22 (calc. 14.13), C 47.20 (calc. 48.47), H 4.88 (calc. 5.08).

Small amounts of the triethyl ester $(100 \mathrm{mg}, 0.34 \mathrm{mmol})$ were added to $3.5 \mathrm{ml}$ of a $1 \mathrm{M}$ aqueous solution of $\mathrm{KOH}$ while cooling with an ice bath. The reaction was stirred until the ester was completely dissolved and then $25 \mathrm{ml}$ ethanol was poured into the solution to precipitate the potassium salt. The product was filtered, washed with ethanol and dried at $75{ }^{\circ} \mathrm{C}$ to obtain $103 \mathrm{mg}(0.28 \mathrm{mmol}, 83 \%)$ potassium-1,3,5-triazine-2,4,6-tricarboxylate dihydrate as colorless needles. Single crystals suitable for single-crystal X-ray diffraction were obtained by repeated recrystallization from aqueous solution at $4{ }^{\circ} \mathrm{C}$.

Elemental analysis (wt. \%): N 11.60 (calc. 11.56), C 20.45 (calc. 19.83), H 0.64 (calc. 1.11).

\section{$X$-ray Structure Determination}

Single-crystal X-ray diffraction data of $\mathrm{K}_{3}\left[\mathrm{C}_{3} \mathrm{~N}_{3}(\mathrm{COO})_{3}\right] \cdot 2 \mathrm{H}_{2} \mathrm{O}$ were collected at $200 \mathrm{~K}$ on a Kappa CCD diffractometer using monochromated Mo- $\mathrm{K}_{\alpha}$ radiation $(\lambda=71.073 \mathrm{pm})$. The diffraction intensities were scaled using the SCALEPACK software package [32] and no additional adsorption correction was applied. The crystal structure was solved by direct methods using the software package SHELXS-97 [33] and refined against $\mathrm{F}^{2}$ by applying the full-matrix least-squares method (SHELXL-97) [34]. The hydrogen positions could be determined from difference Fourier syntheses and were refined isotropically using restraints for oxygen-hydrogen distances. All non-hydrogen atoms were refined anisotropically.

CCDC 784049 contains the supplementary crystallographic data for this paper. These data can be obtained free of charge from The Cambridge Crystallographic Data Centre via www.ccdc.cam.ac.uk/data_request/cif.

\section{FT-Infrared Spectroscopy}

A FTIR spectrum was recorded at ambient conditions between 600 and $4500 \mathrm{~cm}^{-1}$ on a Spektrum BX II FTIR spectrometer (Perkin Elmer) equipped with a DuraSampler diamond ATR device.

\section{Thermal Analysis}

Thermoanalytical measurements were performed with a Thermoanalyzer TG-DTA92 (Setaram) under inert atmosphere (He). The sample was heated in an alumina crucible from room temperature to $500{ }^{\circ} \mathrm{C}$ with a heating rate of $5{ }^{\circ} \mathrm{C} \min ^{-1}$.

\section{Acknowledgments}

The authors thank the Deutsche Forschungsgemeinschaft DFG (project SCHN 377/12) and the Fonds der Chemischen Industrie (FCI) for financial support and Dr. Peter Mayer (Department Chemie, LMU München) for the single-crystal data collection. 
Scheme 1. Molecular precursors for carbon nitride networks comprising the $s$-triazine (1) or $s$-heptazine (2) core.

Scheme 2. Multidentate ligands which are commonly employed as linkers in metal organic frameworks.

Figure 1. Representation of one formula unit of $\mathrm{K}_{3}\left[\mathrm{C}_{3} \mathrm{~N}_{3}(\mathrm{COO})_{3}\right] \cdot 2 \mathrm{H}_{2} \mathrm{O}$. The three triazine tricarboxylate entities present in the crystal structure are labeled A-C. Thermal ellipsoids (except for $\mathrm{H}$ ) are drawn at the $50 \%$ probability level.

Figure 2. Crystal structure of $\mathrm{K}_{3}\left[\mathrm{C}_{3} \mathrm{~N}_{3}(\mathrm{COO})_{3}\right] \cdot 2 \mathrm{H}_{2} \mathrm{O}$ representing the layered structure perpendicular to [100]. Thermal ellipsoids (except for $\mathrm{H}$ ) are drawn at the $50 \%$ probability level.

Figure 3. Crystal structure of $\mathrm{K}_{3}\left[\mathrm{C}_{3} \mathrm{~N}_{3}(\mathrm{COO})_{3}\right] \cdot 2 \mathrm{H}_{2} \mathrm{O}$ representing the stacked arrangement of the triazine tricarboxylate entities. Crystal water molecules are omitted for clarity. The labels A-C refer to Figure 1, indicating which triazine tricarboxylate unit lies on top of the respective column. Thermal ellipsoids are drawn at the $50 \%$ probability level.

Figure 4. FTIR spectrum of $\mathrm{K}_{3}\left[\mathrm{C}_{3} \mathrm{~N}_{3}(\mathrm{COO})_{3}\right] \cdot 2 \mathrm{H}_{2} \mathrm{O}$.

Figure 5. TG (solid) and DTA (dotted) curves of $\mathrm{K}_{3}\left[\mathrm{C}_{3} \mathrm{~N}_{3}(\mathrm{COO})_{3}\right] \cdot 2 \mathrm{H}_{2} \mathrm{O}$, recorded with a heating rate of $5{ }^{\circ} \mathrm{C} \min ^{-1}$.

Table 1. Crystallographic data and details of the structure refinement for $\mathrm{K}_{3}\left[\mathrm{C}_{3} \mathrm{~N}_{3}(\mathrm{COO})_{3}\right] \cdot 2 \mathrm{H}_{2} \mathrm{O}$.

\begin{tabular}{|c|c|}
\hline molar mass / $\mathrm{g} \mathrm{mol}^{-1}$ & 363.41 \\
\hline crystal system & triclinic \\
\hline space group & $P \overline{1}$ (no. 2) \\
\hline $\mathrm{T} / \mathrm{K}$ & 200 \\
\hline diffractometer & Nonius Kappa-CCD \\
\hline radiation, $\lambda / \mathrm{pm}$ & Mo-K ${ }_{\alpha}, 71.073$ \\
\hline$a / \mathrm{pm}$ & $696.63(14)$ \\
\hline$b / \mathrm{pm}$ & $1748.5(3)$ \\
\hline$c / \mathrm{pm}$ & $1756.0(3)$ \\
\hline$\alpha / \operatorname{deg}$ & $119.73(3)$ \\
\hline$\beta / \operatorname{deg}$ & $91.96(3)$ \\
\hline$\gamma / \operatorname{deg}$ & $93.84(3)$ \\
\hline$V / 10^{6} \mathrm{pm}^{3}$ & $1847.6(8)$ \\
\hline$Z$ & 6 \\
\hline calculated density $/ \mathrm{g} \mathrm{cm}^{-3}$ & 1.960 \\
\hline crystal size $/ \mathrm{mm}^{3}$ & $0.70 \times 0.07 \times 0.05$ \\
\hline absorption coefficient $/ \mathrm{mm}^{-1}$ & 1.150 \\
\hline diffraction range & $3.26^{\circ} \leq \theta \leq 27.54^{\circ}$ \\
\hline index range & $\begin{array}{l}-8 \leq h \leq 9,-22 \leq k \leq 22 \\
-22 \leq l \leq 22\end{array}$ \\
\hline parameters / restraints & $577 / 16$ \\
\hline total no. of reflections & 14291 \\
\hline no. of independent reflections & 8452 \\
\hline no. of observed reflections & 5617 \\
\hline $\begin{array}{l}\text { min./max. residual electron } \\
\text { density } / 10^{6} \mathrm{pm}^{3}\end{array}$ & $-0.679 /+0.984$ \\
\hline GooF & 1.047 \\
\hline final $\mathrm{R}$ indices $[I>2 \sigma(I)]$ & $R 1=0.0513, w R 2=0.1068^{[a]}$ \\
\hline final $\mathrm{R}$ indices (all data) & $R 1=0.0868, w R 2=0.1228^{[\mathrm{a}]}$ \\
\hline
\end{tabular}


Table 2. Selected bond lengths (in pm) and angles (in deg) in $\mathrm{K}_{3}\left[\mathrm{C}_{3} \mathrm{~N}_{3}(\mathrm{COO})_{3}\right] \cdot 2 \mathrm{H}_{2} \mathrm{O}$, standard deviations in parentheses.

\begin{tabular}{|c|c|c|c|c|c|c|c|c|c|c|c|}
\hline K1 - O4 & $292.6(3)$ & $\mathrm{K} 3-\mathrm{O} 16$ & $281.0(3)$ & K5 - N4 & $278.2(3)$ & K8 - O8 & $284.0(3)$ & $\mathrm{N} 3-\mathrm{C} 3$ & $132.9(4)$ & $\mathrm{N} 2-\mathrm{C} 2-\mathrm{C} 5$ & $117.9(3)$ \\
\hline $\mathrm{K} 1-\mathrm{O} 5$ & $281.7(3)$ & $\mathrm{K} 3-\mathrm{O} 16$ & $283.7(3)$ & $\mathrm{K} 6-\mathrm{O} 2$ & $278.6(3)$ & K8 - O9 & $296.2(3)$ & $\mathrm{C} 4-\mathrm{O} 1$ & $123.9(4)$ & $\mathrm{N} 2-\mathrm{C} 3-\mathrm{C} 6$ & $118.2(3)$ \\
\hline $\mathrm{K} 1-\mathrm{O} 14$ & 279.1(3) & $\mathrm{K} 3-\mathrm{O} 21$ & $282.2(3)$ & K6 - O6 & 287.2(3) & $\mathrm{K} 8$ - O22 & $278.2(3)$ & $\mathrm{C} 4-\mathrm{O} 2$ & $125.0(4)$ & N3 - C3 - C6 & $117.3(3)$ \\
\hline $\mathrm{K} 1$ - O14 & $284.6(3)$ & K3 - N1 & $279.7(3)$ & K6 - O18 & $280.0(3)$ & K8 - N5 & 279.7(3) & $\mathrm{C} 1-\mathrm{C} 4$ & $153.0(4)$ & $\mathrm{O} 1-\mathrm{C} 4-\mathrm{O} 2$ & $127.5(3)$ \\
\hline K1 - O19 & $280.3(3)$ & $\mathrm{K} 4-\mathrm{O} 1$ & $287.5(3)$ & K6 - O18 & $293.0(3)$ & K9- O7 & $274.4(3)$ & $\mathrm{C} 2-\mathrm{C} 5$ & $154.2(5)$ & $\mathrm{O} 4-\mathrm{C} 5-\mathrm{O} 3$ & $127.8(3)$ \\
\hline $\mathrm{K} 1$ - N2 & $278.6(3)$ & K4 - O9 & $276.9(3)$ & K6 - O20 & $285.4(4)$ & K9 - O13 & $274.0(3)$ & $\mathrm{C} 3$ - C6 & $153.0(5)$ & O6 - C6 - O5 & $128.5(4)$ \\
\hline $\mathrm{K} 2-\mathrm{O} 4$ & $286.3(3)$ & K4 - O16 & $290.3(3)$ & $\mathrm{K} 6-\mathrm{O} 24$ & $284.7(4)$ & K9- O18 & 297.1(3) & $\mathrm{C} 2-\mathrm{N} 1-\mathrm{C} 1$ & $115.4(3)$ & $\mathrm{O} 1-\mathrm{C} 4-\mathrm{C} 1$ & $117.5(3)$ \\
\hline $\mathrm{K} 2-\mathrm{O} 12$ & $281.2(3)$ & K4 - O17 & $286.5(3)$ & K6 - N3 & 279.3(3) & K9 - O20 & 275.7(3) & $\mathrm{C} 2-\mathrm{N} 2-\mathrm{C} 3$ & $115.4(3)$ & $\mathrm{O} 2-\mathrm{C} 4-\mathrm{C} 1$ & $115.0(3)$ \\
\hline $\mathrm{K} 2-\mathrm{O} 14$ & $284.4(3)$ & $\mathrm{K} 4-\mathrm{O} 21$ & $273.4(3)$ & $\mathrm{K} 7-\mathrm{O} 6$ & $277.8(3)$ & $\mathrm{K} 9-\mathrm{O} 24$ & $274.0(4)$ & $\mathrm{C} 3-\mathrm{N} 3-\mathrm{C} 1$ & $115.7(3)$ & $\mathrm{O} 3-\mathrm{C} 5-\mathrm{C} 2$ & $115.2(3)$ \\
\hline $\mathrm{K} 2-\mathrm{O} 19$ & $275.7(3)$ & K4 - N8 & 281.8(3) & $\mathrm{K} 7-\mathrm{O} 12$ & 291.8(3) & $\mathrm{N} 1-\mathrm{C} 1$ & $133.8(4)$ & $\mathrm{N} 2-\mathrm{C} 2-\mathrm{N} 1$ & $124.7(3)$ & $\mathrm{O} 5-\mathrm{C} 6-\mathrm{C} 3$ & $115.3(3)$ \\
\hline $\mathrm{K} 2-\mathrm{O} 23$ & $273.4(3)$ & K5 - O1 & $280.5(3)$ & K7 - O19 & $295.5(3)$ & $\mathrm{N} 1-\mathrm{C} 2$ & $133.4(4)$ & $\mathrm{N} 3-\mathrm{C} 3-\mathrm{N} 2$ & $124.5(3)$ & O6- C6 - C3 & 116.1(3) \\
\hline K2 - N9 & $280.7(3)$ & K5 - O7 & 291.3(3) & $\mathrm{K} 7-\mathrm{O} 23$ & 285.2(3) & $\mathrm{N} 2-\mathrm{C} 2$ & 133.1(4) & $\mathrm{N} 1-\mathrm{C} 1-\mathrm{C} 4$ & $117.9(3)$ & & \\
\hline K3 - O1 & $287.6(3)$ & K5 - O11 & 277.1(3) & K7 - N6 & 279.1(3) & $\mathrm{N} 2-\mathrm{C} 3$ & $133.9(4)$ & $\mathrm{N} 3-\mathrm{C} 1-\mathrm{C} 4$ & $117.8(3)$ & & \\
\hline $\mathrm{K} 3-\mathrm{O} 3$ & 281.1(3) & $\mathrm{K} 5$ - O24 & $280.0(5)$ & $\mathrm{K} 8-\mathrm{O} 4$ & $278.7(3)$ & N3 - C1 & $133.6(4)$ & $\mathrm{N} 1-\mathrm{C} 2-\mathrm{C} 5$ & $117.4(3)$ & & \\
\hline
\end{tabular}

Table 3. Donor-acceptor distances and donor-hydrogen-acceptor angles (in $\mathrm{pm} / \mathrm{deg}$ ) for the hydrogen bonding network in $\mathrm{K}_{3}\left[\mathrm{C}_{3} \mathrm{~N}_{3}(\mathrm{COO})_{3}\right] \cdot 2 \mathrm{H}_{2} \mathrm{O}$.

\begin{tabular}{|c|c|c|c|c|c|}
\hline $\mathrm{D}-\mathrm{H} \cdots \mathrm{A}$ & $\mathrm{D} \cdots \mathrm{A}$ & $<\mathrm{D}-\mathrm{H} \cdots \mathrm{A}$ & $\mathrm{D}-\mathrm{H} \cdots \mathrm{A}$ & $\mathrm{D} \cdots \mathrm{A}$ & $<\mathrm{D}-\mathrm{H} \cdots \mathrm{A}$ \\
\hline 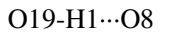 & 283.9 & 154.79 & $\mathrm{O} 22-\mathrm{H} 7 \cdots \mathrm{O} 15$ & 266.5 & 173.09 \\
\hline $\mathrm{O} 19-\mathrm{H} 2 \cdots \mathrm{O} 5$ & 272.0 & 159.35 & $\mathrm{O} 22-\mathrm{H} 8 \cdots \mathrm{O} 11$ & 292.8 & 176.50 \\
\hline $\mathrm{O} 20-\mathrm{H} 4 \cdots \mathrm{O} 10$ & 279.6 & 166.63 & $\mathrm{O} 23-\mathrm{H} 10 \cdots \mathrm{O} 8$ & 290.1 & 167.27 \\
\hline $\mathrm{O} 21-\mathrm{H} 5 \cdots \mathrm{O} 3$ & 270.6 & 160.13 & $\mathrm{O} 24-\mathrm{H} 12 \cdots \mathrm{O} 17$ & 266.6 & 155.49 \\
\hline $\mathrm{O} 21-\mathrm{H} 6 \cdots \mathrm{O} 11$ & 281.4 & 169.61 & & & \\
\hline
\end{tabular}


[1] G. Goglio, D. Foy, G. Demazeau, Mater. Sci. Eng. R 2008, 58, 195.

[2] E. Kroke, M. Schwarz, Coord. Chem. Rev. 2004, 248, 493.

[3] A. Thomas, A. Fischer, F. Goettmann, M. Antonietti, J.-O. Müller, R. Schlögl, J. M. Carlsson, J. Mater. Chem. 2008, 18,4893

[4] E. G. Gillan, Chem. Mater. 2000, 12, 3906.

[5] T. Komatsu, J. Mater. Chem. 2001, 11, 799.

[6] E. Kroke, M. Schwarz, E. Horath-Bordon, P. Kroll, B. Noll, A. D. Norman, New J. Chem. 2002, $26,508$.

[7] B. V. Lotsch, M. Döblinger, J. Sehnert, L. Seyfarth, J. Senker, O. Oeckler, W. Schnick, Chem. Eur. J. 2007, 13, 4969.

[8] D. R. Miller, J. R. Holst, E. G. Gillan, Inorg. Chem. 2007, 46, 2767.

[9] A. U. Czaja, N. Trukhan, U. Müller, Chem. Soc. Rev. 2009, 38, 1284.

[10] R. J. Kuppler, D. J. Timmons, Q.-R. Fang, J.-R. Li, T. A. Makal, M. D. Young, D. Yuan, D. Zhao, W. Zhuang, H.C. Zhou, Coord. Chem. Rev. 2009, 253, 3042.

[11] S. S.-Y. Chui, S. M.-F. Lo, J. P. H. Charmant, A. G. Orpen, I. D. Williams, Science 1999, 283, 1148.

[12] J. Kim, B. Chen, T. M. Reineke, H. Li, M. Eddaoudi, D. B. Moler, M. O'Keeffe, O. M. Yaghi, J. Am. Chem. Soc. 2001, 123, 8239 .

[13] O. M. Yaghi, G. Li, H. Li, Nature 1995, 378, 703.

[14] D. N. Dybtsev, H. Chun, K. Kim, Chem. Commun. 2004, 1594.

[15] M.-X. Li, Z.-X. Miao, M. Shao, S.-W. Liang, S.-R. Zhu, Inorg. Chem. 2008, 47, 4481.

[16] D. Sun, S. Ma, Y. Ke, T. M. Petersen, H.-C. Zhou, Chem. Commun. 2005, 2663.

[17] Y. K. Park, S. B. Choi, H. Kim, K. Kim, B.-H. Won, K. Choi, J.-S. Choi, W.-S. Ahn, N. Won, S. Kim, D. H. Jung, S.-H. Choi, G.-H. Kim, S.-S. Cha, Y. H. Jhon, J. K. Yang, J. Kim, Angew. Chem. 2007, 119, 8378; Angew. Chem. Int. Ed. 2007, 46, 8230 .

[18] S. Ma, X.-S. Wang, D. Yuan, H.-C. Zhou, Angew. Chem. 2008, 120, 4198; Angew. Chem. Int. Ed. 2008, 47, 4130.

[19] D. Sun, S. Ma, Y. Ke, D. J. Collins, H.-C. Zhou, J. Am. Chem. Soc. 2006, 1258, 3896.

[20] S. Ma, D. Sun, M. Ambrogio, J. A. Fillinger, S. Parkin, H.-C. Zhou, J. Am. Chem. Soc. 2007, 129, 1858.

[21] Y. Ke, D. J. Collins, D. Sun, H.-C. Zhou, Inorg. Chem. 2006, 45, 1897.

[22] C. Grundmann, E. Kober, J. Org. Chem. 1956, 21, 1392.

[23] J.-R. Galán-Mascarós, J.-M. Clemente-Juan, K. R. Dunbar, Dalton Trans. 2002, 13, 2710.

[24] S.-J. Chen, U. Behrens, E. Fischer, R. Mews, F. Pauer, G. M. Sheldrick, D. Stalke, W.-D. Stohrere, Chem. Ber. 1993, 126, 2601.

[25] B. V. Lotsch, W. Schnick, Chem. Mater. 2006, 18, 1891.

[26] T. Steiner, Angew. Chem. 2002, 114, 50; Angew. Chem. Int. Ed. 2002, 41, 48.

[27] R. D. Shannon, Acta Crystallogr., Sect. A 1976, 32, 751.

[28] E. Horvath-Bordon, E. Kroke, I. Svoboda, H. Fueß, R. Riedel, S. Neeraj, A. K. Cheetham, Dalton Trans. 2004,

3900 .

[29] E. Irran, B. Jürgens, W. Schnick, Chem. Eur. J. 2001, 7, 5372.

[30] A. Sattler, W. Schnick, Eur. J. Inorg. Chem. 2009, 4972.

[31] E. Ott, Ber. Dtsch. Chem. Ges. 1919, 52, 656.

[32] Z. Otwinowski, W. Minor, Methods Enzymol. 1997, 276, 307.

[33] G. M. Sheldrick, SHELXS-97, Program for the Solution of Crystal Structures, Universität Göttingen 1997.

[34] G. M. Sheldrick, SHELXL-97, Program for the Refinement of Crystal Structures, Universität Göttingen 1997. 


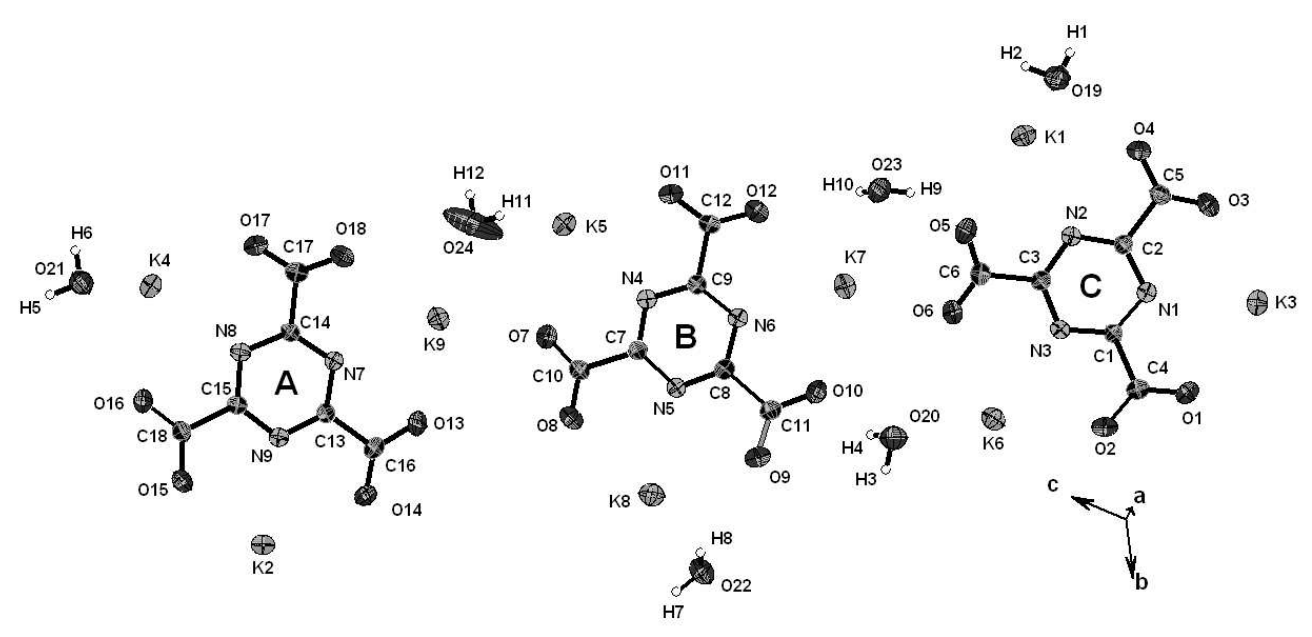

$327 \times 159 m m(96 \times 96$ DPI) 


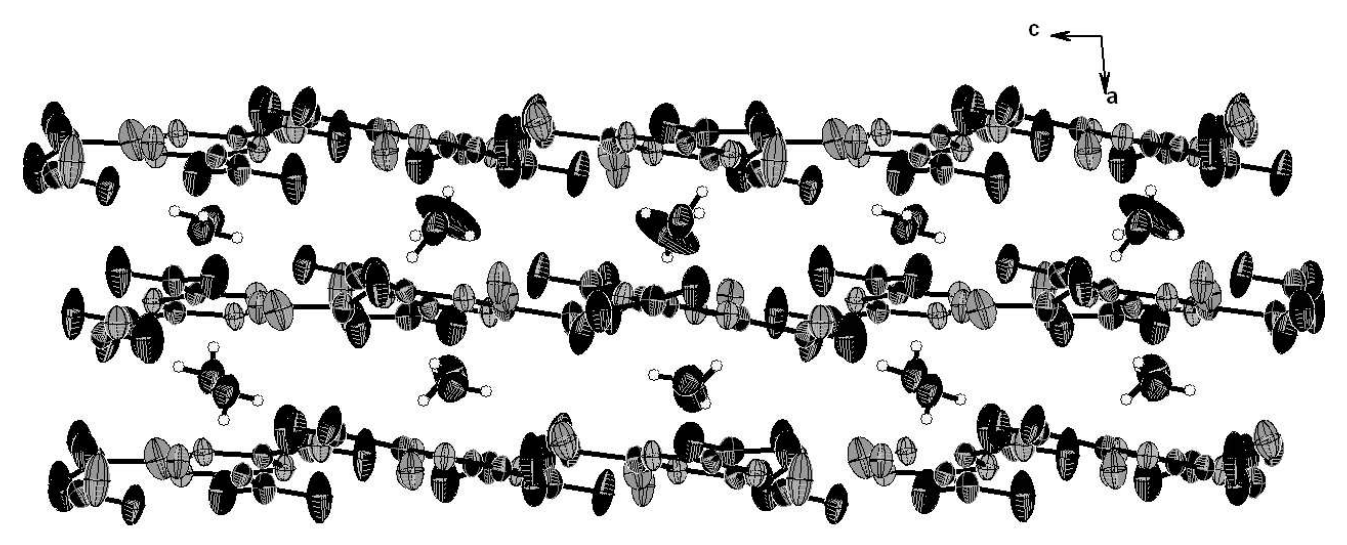

$336 \times 146 \mathrm{~mm}(96 \times 96$ DPI) 

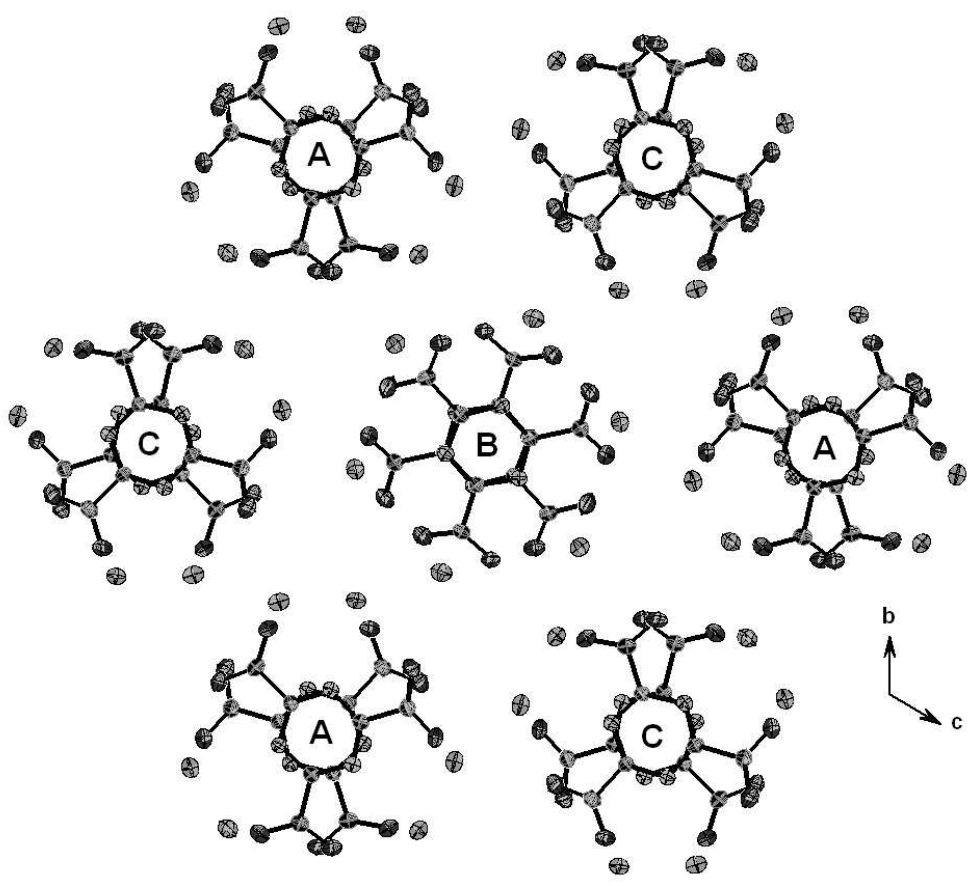

$331 \times 225 \mathrm{~mm}(96 \times 96$ DPI) 


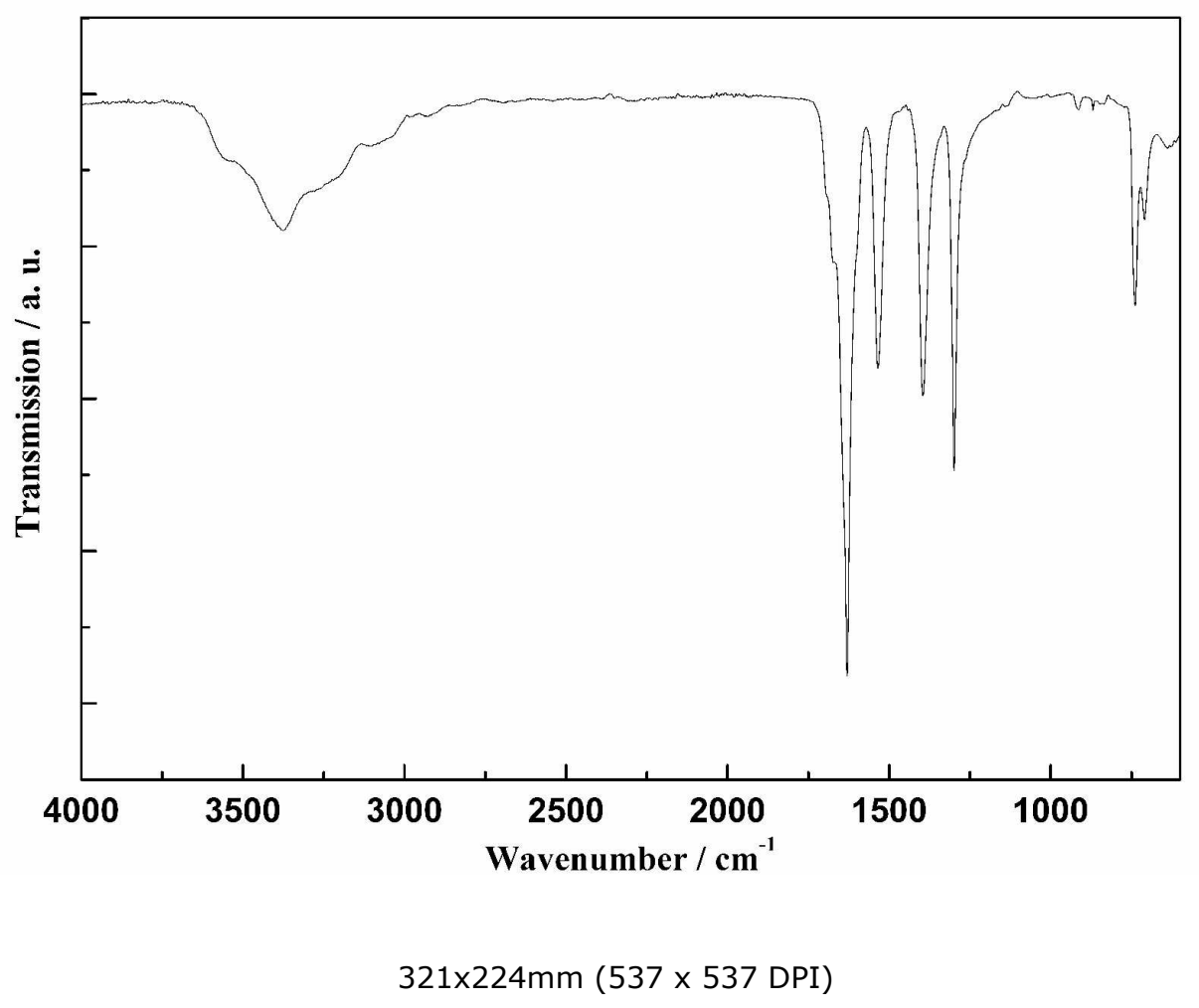


1

2

3

4

5

6

7

8

9

10

11

12

14

15

16

17

18

19

20

21

22

23

24

25

26

27

28

29

30

31

32

33

34

35

36

37

38

39

40

41

42

43

44

45

46

47

48

49

50

51

52

53

54

55

56

57

58

59

60

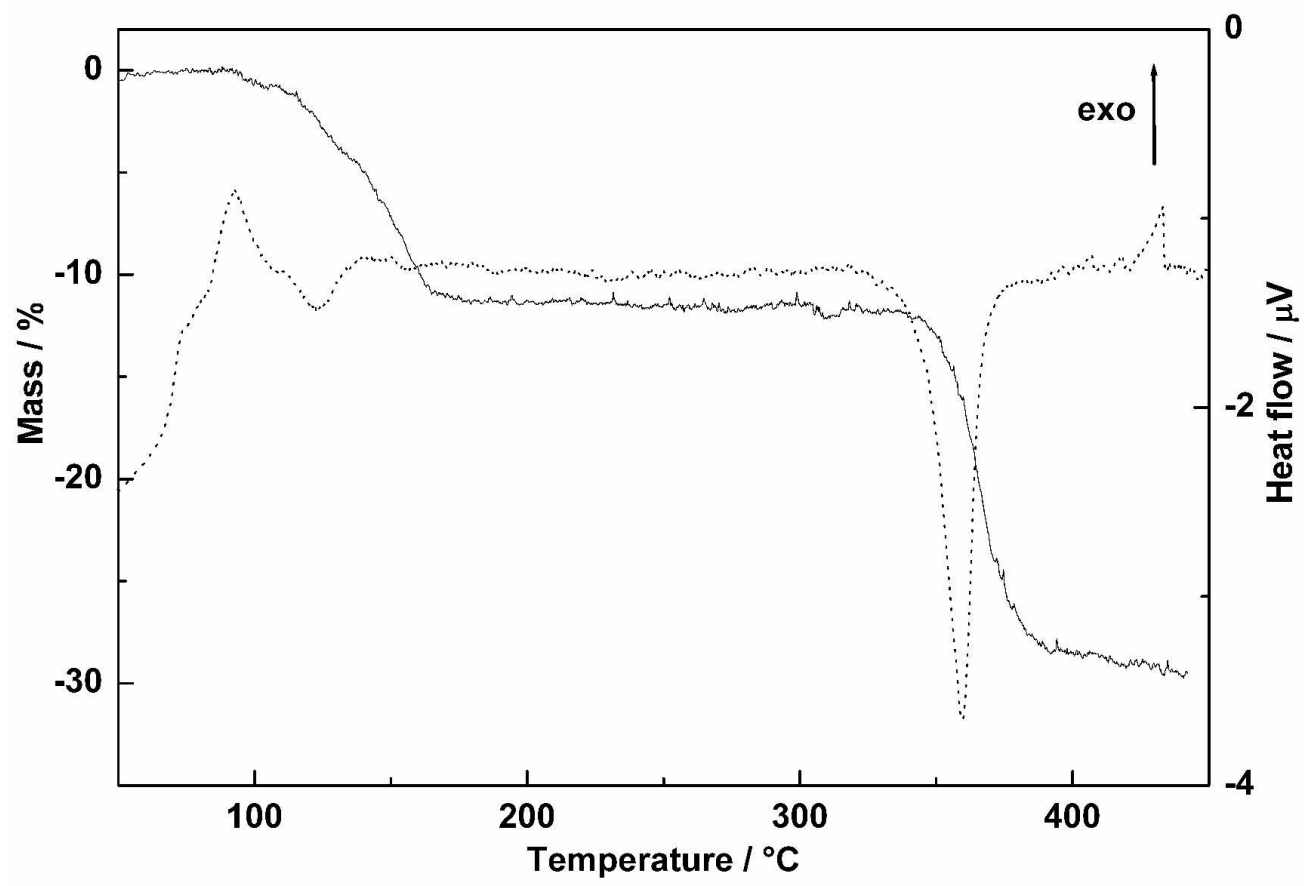

$326 \times 227 \mathrm{~mm}(537 \times 537$ DPI) 

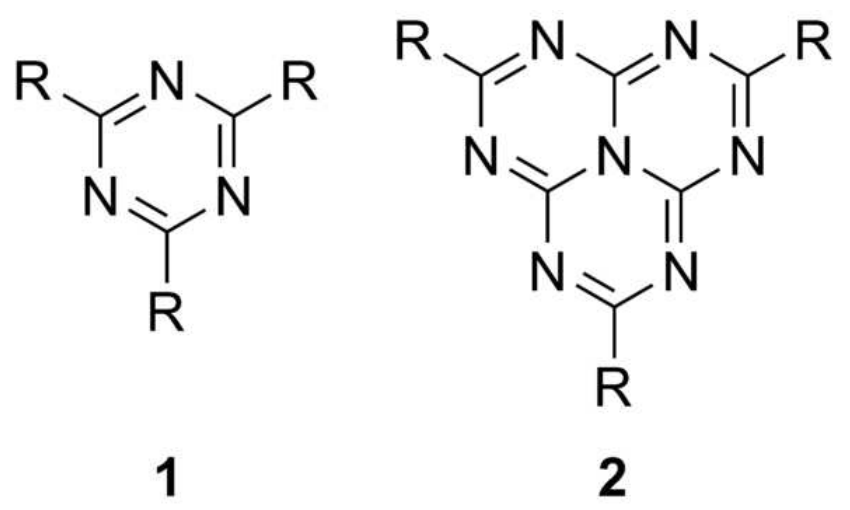

$$
\begin{array}{ll}
\text { a } & \mathrm{R}=\mathrm{NH}_{2} \\
\text { b } & \mathrm{R}=\mathrm{OH} \\
\text { c } & \mathrm{R}=\mathrm{Cl} \\
\text { d } & \mathrm{R}=\mathrm{N}_{3} \\
\text { e } & \mathrm{R}=\mathrm{CN} \\
\text { f } & \mathrm{R}=\mathrm{COOH}
\end{array}
$$

$39 \times 15 \mathrm{~mm}(600 \times 600 \mathrm{DPI})$ 


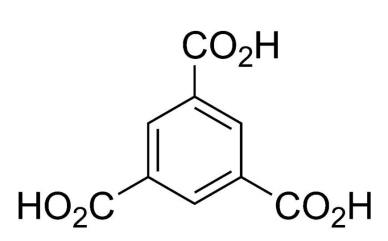

3<smiles>O=C(O)c1ccc(-c2nc(-c3ccc(C(=O)O)cc3)nc(-c3ccc(C(=O)O)cc3)n2)cc1</smiles><smiles>O=C(O)c1ccc(C2=NCN3CNC(c4ccc(C(=O)O)cc4)=NC3=N2)cc1</smiles>

$123 \times 105 \mathrm{~mm}(600 \times 600 \mathrm{DPI})$ 